\title{
Effect of Cooling Rate on ZST, LIT and ZDT of Carbon Steels Near Melting Point
}

\author{
Young Mok WON, Kyung-hyun KIM, () Tae-jung YEO and Kyu Hwan OH
}

School of Materials Science and Engineering and Research Institute of Advanced Materials, Seoul National University, San 56-1, Shinrim-dong, Kwanak-ku, Seoul 151-742, Korea.

1) Technology Development Group, M/U FAB. Department, Semiconductor R \& D, Samsung Electronics, Yongin, Kyungi-Do 449-900, Korea.

(Received on February 23, 1998; accepted in final form on June 3,1998)

The effect of cooling rate on the characteristic temperatures such as liquidus temperature $\left(T_{L}\right)$, zero strength temperature (ZST), liquid impenetrable temperature (LIT) and zero ductility temperature (ZDT) has been investigated by calculating the non-equilibrium pseudo binary Fe-C phase diagram. The effect of cooling rate on $T_{L}$ was not significant. The effect of cooling rate on ZST, LIT and ZDT was significant due to segregation of solute elements at the final stage of solidification. Using the microsegregation analysis proposed by Ueshima, the calculated temperatures at the solid fractions of 0.75 and 0.99 corresponded to the experimentally measured ZST and ZDT, respectively. Prediction equation on ZST, LIT and ZDT, which can take into account cooling rate and steel composition, was proposed. At given steel compositions and cooling rates, the suggested prediction equation on ZST, LIT and ZDT could successfully describe the experimentally measured data and the calculated data from microsegregation analysis.

KEY WORDS: cooling rate; non-equilibrium pseudo binary $\mathrm{Fe}-\mathrm{C}$ phase diagram; microsegregation; liquidus temperature $\left(T_{L}\right)$; zero strength temperature $(\mathrm{ZST})$; liquid impenetrable temperature (LIT); zero ductility temperature (ZDT).

\section{Introduction}

Continuous casting process becomes the mainstay of the modern steelmaking. The continuously cast products have many advantages over ingot casting, such as improved productivity, reduced energy consumption, reduced cost, and high quality. ${ }^{1)}$ However, at higher casting speeds and larger reductions, internal and longitudinal surface cracks can easily occur. In recent years, internal and longitudinal surface cracks have again become an important concern as it was twenty years ago.

During continuous casting of steels, internal and longitudinal surface cracks tend to occur in a brittle temperature range by thermal and mechanical deformation. ${ }^{2)}$ To prevent the occurrence of these cracks in continuous casting slabs, better understandings on the melting behavior and the mechanical properties near the melting point is essential. The mechanical properties can be characterized by four characteristic temperatures; zero strength temperature (ZST), zero ductility temperature (ZDT), liquid impenetrable temperature (LIT) and liquidus temperature $\left(T_{\mathbf{L}}\right){ }^{2)}$ Melting starts on heating at a temperature lower than a fully solidifying temperature on cooling and the ZST, ZDT and LIT on heating are different from those on cooling. ${ }^{3)} \mathrm{Yu}$ et al. ${ }^{4)}$ reported that, in low carbon steel, ZST on heating was lower than the solidus temperature and nearly equal to ZDT, but ZST on cooling was higher than the equilibrium solidus temperature and the difference between ZST and ZDT on cooling was larger than that on heating.

Howe ${ }^{5)}$ reported that the liquidus temperature calculated with equivalent carbon content has been adequate for many classes of steel, but the solidus temperature calculated with equivalent carbon content and the cooling rate, has been valid only in very dilute steel compositions. The solidus temperature at a cooling rate of $1.0^{\circ} \mathrm{C} / \mathrm{sec}$ is lower about $20-45^{\circ} \mathrm{C}$ at various steel compositions than that at a cooling rate of $0.1^{\circ} \mathrm{C} / \mathrm{sec}$. However, the effect of cooling rate on ZST, LIT and ZDT using the nonequilibrium pseudo binary $\mathrm{Fe}-\mathrm{C}$ phase diagram has not been reported yet.

The objective of present study is to predict ZST, LIT and ZDT at various steel compositions and cooling rate conditions. To accomplish this, the non-equilibrium pseudo binary $\mathrm{Fe}-\mathrm{C}$ phase diagram has been calculated and the fitting equation for ZST, LIT and ZDT has been proposed from experimentally measured data by previous researchers. ${ }^{4,6-10)}$

\section{Analysis}

\subsection{Calculation of Microsegregation}

The microsegregation in a continuously cast strand has been calculated using the direct difference method suggested by Ueshima et al. ${ }^{11)} \mathrm{Kim}$ et al. ${ }^{2,12)}$ have explained the deformation behavior of mushy zone and 
longitudinal surface cracks at various steel compositions during continuous casting.

Figure 1(a) shows a schematic diagram of growing dendrites in the continuously cast strand. The transverse cross section of dendrites is approximated by a regular hexagon, one sixth of which is shown in Fig. 1(b). The complete mixing of solute elements in the liquid phase and local equilibrium at liquid $/ \delta$, liquid $/ \gamma$ and $\delta / \gamma$ interfaces are assumed. The diffusion of solute in solid and liquid phases along the axial direction of dendrite is assumed to be negligible. $\gamma$-Fe phase develops from the interface between $\delta$-Fe and liquid phase. In the solid/liquid and $\delta / \gamma$ interfaces, the solute concentrations are assumed to be in the local equilibrium. During $\delta / \gamma$ transformation, silicon, phosphorus and sulfur are redistributed from $\gamma$-Fe to $\delta$ - $\mathrm{Fe}$, because the equilibrium distribution coefficient $k^{y / \delta}$ is less than 1, but carbon and manganese are redistributed from $\delta$-Fe to $\gamma$-Fe due to $k^{y / \delta}>1$. Using the assumptions of the complete mixing in liquid phase, no axial diffusion and local equilibrium, the solute distributions in the three phases, $\delta$ - $\mathrm{Fe}, \gamma-\mathrm{Fe}$ and liquid, were calculated. The calculation was made

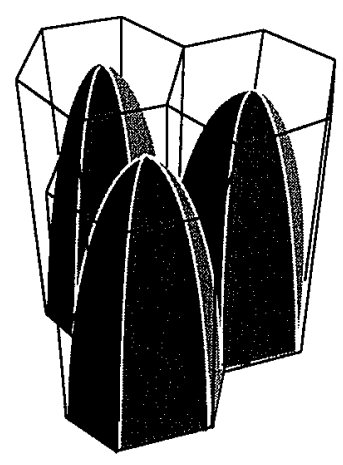

(a)

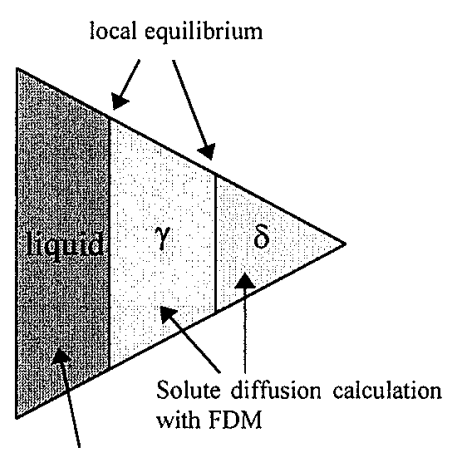

complete mixing (b)

Fig. 1. (a) Schematic drawing showing the morphology of the dendrite array and (b) the transverse cross section assumed in the finite difference simulation. by dividing the triangular transverse cross section into 100 meshes parallel to vertical lines. When the liquidus temperature, $T_{\mathrm{L}}$, and the $\delta / \gamma$ transformation temperature, $T_{\mathrm{Ar} 4}$, become equal to the actual temperature of one mesh, the solidification and $\delta / \gamma$ transformation in one mesh are assumed to be completed and the interfaces move to the next mesh. $T_{\mathrm{L}}$ and $T_{\mathrm{Ar} 4}$ are calculated using the following equations. ${ }^{13,14)}$

$$
\begin{array}{rl}
T_{\mathrm{L}}=1 & 536-78(\mathrm{wt} \% \mathrm{C})-7.6(\mathrm{wt} \% \mathrm{Si})-4.9(\mathrm{wt} \% \mathrm{Mn}) \\
- & 34.4(\mathrm{wt} \% \mathrm{P})-38(\mathrm{wt} \% \mathrm{~S}) \ldots \ldots \ldots \ldots . . . . . . . . . . .(1) \\
T_{\mathrm{Ar} 4}= & 1392+1122(\mathrm{wt} \% \mathrm{C})-60(\mathrm{wt} \% \mathrm{Si}) \\
& +12(\mathrm{wt} \% \mathrm{Mn})-140(\mathrm{wt} \% \mathrm{P})-160(\mathrm{wt} \% \mathrm{~S}) \ldots(2)
\end{array}
$$

The equilibrium distribution coefficients and diffusion coefficients of the solute elements are given in Table $1 .{ }^{10}$ The solid fraction, $f_{\mathrm{s}}, \delta$-Fe fraction, ${ }^{\delta} f_{\mathrm{s}}$, and $\gamma$-Fe fraction, ${ }^{\gamma} f_{\mathrm{s}}$, in the solid or/and liquid phase were calculated as a function of temperature at various steel compositions and cooling rates in Table 2 .

\subsection{Equation for Characteristic Temperatures}

In order to describe the characteristic temperatures such as ZST, LIT and ZDT as a function of steel composition and cooling rate, we used the Clyne-Kurz microsegregation model ${ }^{15)}$ which takes into account the solute diffusion in solid. The relation between the solid fraction and the temperature can be expressed as follows

$$
\begin{gathered}
f_{\mathrm{s}}=\left(\frac{1}{1-2 \Omega k}\right)\left[1-\left(\frac{T_{\mathrm{f}}-T}{T_{\mathrm{f}}-T_{\mathrm{L}}}\right)^{(1-2 \Omega k) /(k-1)}\right] \\
\Omega=\alpha(1-\exp (-1 / \alpha))-\frac{1}{2} \exp (-1 / 2 \alpha) \\
\alpha=\frac{4 D_{\mathrm{s}} t_{\mathrm{f}}}{\lambda^{2}} \ldots \ldots \ldots \ldots \ldots \ldots \ldots \ldots \ldots \ldots \ldots \ldots \ldots \ldots
\end{gathered}
$$

where $T_{\mathrm{f}}$ is the melting temperature of pure iron, $T_{\mathrm{L}}$ is the liquidus temperature, $k$ is the equilibrium redistribution coefficient of solute element, $\alpha$ and $\Omega$ are parameters expressing the degree of back diffusion of solute element,

Table 1. Equilibrium distribution coefficients and diffusion coefficients of solute elements. ${ }^{11)}$

\begin{tabular}{cccccc}
\hline Element & $k^{8 \mathrm{~h}}$ & $k^{\text {nL }}$ & $k^{8 / \gamma}$ & $\mathrm{D}^{\delta}\left(10^{-4} \times \mathrm{m}^{2} / \mathrm{s}\right)$ & $\mathrm{D}^{\gamma}\left(10^{-4} \times \mathrm{m}^{2} / \mathrm{s}\right)$ \\
\hline $\mathrm{C}$ & 0.19 & 0.34 & 1.79 & $0.0127 \exp (-81379 / \mathrm{RT})$ & $0.0761 \exp (-143511 / \mathrm{RT})$ \\
$\mathrm{Si}$ & 0.77 & 0.52 & 0.68 & $8.0 \exp (-248948 / \mathrm{RT})$ & $0.3 \exp (-251458 / \mathrm{RT})$ \\
$\mathrm{Mn}$ & 0.76 & 0.78 & 1.03 & $0.76 \exp (-224430 / \mathrm{RT})$ & $0.055 \exp (-249366 / \mathrm{RT})$ \\
$\mathrm{P}$ & 0.23 & 0.13 & 0.57 & $2.9 \exp (-230120 / \mathrm{RT})$ & $0.01 \exp (-182841 / \mathrm{RT})$ \\
$\mathrm{S}$ & 0.05 & 0.035 & 0.70 & $4.56 \exp (-214639 / \mathrm{RT})$ & $2.4 \exp (-223425 / \mathrm{RT})$ \\
\hline
\end{tabular}

Table 2. Chemical compositions of carbon steels $(w t \%)$ and cooling rates. $\left({ }^{\circ} \mathrm{C} / \mathrm{sec}\right)$

\begin{tabular}{cccccccc}
\hline Sample & $\mathrm{C}$ & $\mathrm{Si}$ & $\mathrm{Mn}$ & $\mathrm{P}$ & $\mathrm{S}$ & $\dot{T}$ & ref. \\
\hline $\mathrm{B} 1$ & $0.0-0.8$ & 0.34 & 1.52 & 0.012 & 0.015 & 10 & $6)$ \\
$\mathrm{C} 1$ & $0.0-0.8$ & 0.015 & 1.05 & 0.0009 & 0.0008 & 0.17 & $7)$ \\
$\mathrm{A}$ & $0.001-0.83$ & $0.01-0.26$ & $0.03-1.33$ & $0.007-0.11$ & $0.001-0.018$ & 4 & $4)$ \\
B & $0.015-1.0$ & $0.21-0.42$ & $0.56-1.66$ & $0.008-0.014$ & $0.011-0.02$ & 10 & $6)$ \\
C & $0.06-0.6$ & $0.005-0.015$ & $1.03-1.06$ & $0.0005-0.0009$ & $0.0005-0.0008$ & 0.17 & $7)$ \\
D & $0.13-0.82$ & $0.005-0.24$ & $0.78-1.08$ & $0.0005-0.11$ & $0.0006-0.062$ & 0.17 & $8)$ \\
E & $0.003-1.6$ & $0.01-0.23$ & $0.01-0.5$ & $0.0006-0.004$ & $0.0003-0.004$ & 20 & $9)$ \\
F & $0.04-0.67$ & $0.01-0.24$ & $0.28-0.81$ & $0.001-0.085$ & $0.001-0.008$ & 20 & $10)$ \\
\hline
\end{tabular}




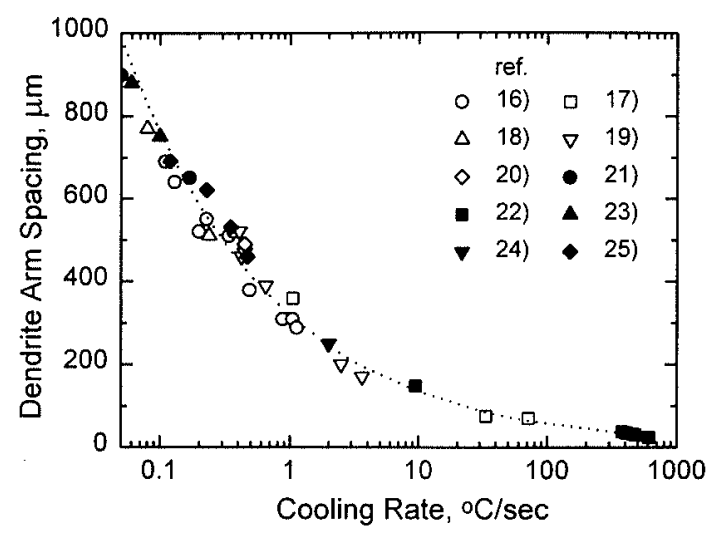

Fig. 2. Comparison of the calculated and measured dendrite arm spacings ${ }^{16-25)}$ as a function of cooling rate.

$D_{\mathrm{s}}$ is the solute diffusion coefficient in the solid, $t_{\mathrm{f}}$ is the local solidification time, $\lambda$ is the dendrite arm spacing.

The dendrite arm spacing has been modeled as a function of cooling rate. Using the measured dendrite arm spacings at the various cooling rates, ${ }^{16-25)}$ it has been determined that the relationship between the dendrite arm spacing and cooling rate, $\dot{T}$, has been expressed as follows.

$$
\lambda=B \cdot \dot{T}^{-n}
$$

where $B$ and $n$ are experimental constant parameters. The value of $B$ and $n$ are obtained to be 319.4 and 0.378 by the best fitting of the measured dendrite arm spacings, respectively. Figure 2 shows the calculated and measured dendrite arm spacings as a function of cooling rate at the various steel compositions. The dendrite arm spacing is seen to be well described by Eq. (6) in the given cooling rate.

The local solidification time, $t_{\mathrm{f}}$, can be given as follows.

$$
t_{\mathrm{f}}=\frac{\Delta T_{\mathrm{S}}}{\dot{T}}
$$

where $\Delta T_{\mathrm{S}}$ is the solidification temperature range. From Eqs. (5), (6) and (7), $\alpha$ can be given as follows.

$$
\alpha=\frac{4 D_{\mathrm{s}} \Delta T_{\mathrm{S}}}{B^{2}} \cdot \dot{T}^{-1+2 n}=A \cdot \dot{T}^{-m}
$$

where $A$ is an experimental constant parameter indicating the relation between the solute diffusion coefficient and solidification temperature range, and the value of $m$ is obtained to be 0.244 .

Above Eqs. (3), (4) and (8) reduce to the Scheil equation as $\alpha$ and $\Omega$ approaches zero (no back diffusion in the solid), i.e. cooling rate becomes infinity, and to the lever rule as $\alpha$ approaches infinity and $\Omega$ approaches 0.5 , i.e. cooling rate becomes zero.

To describe characteristic temperature, Eq. (3) can be expressed as follows.

$$
T=T_{\mathrm{f}}-\left(T_{\mathrm{f}}-T_{\mathrm{L}}\right)\left[1-f_{\mathrm{s}}(1-2 \Omega k)\right]^{(k-1) /(1-2 \Omega k)}
$$

$T_{\mathrm{f}}$ is the melting point of pure iron as $1536^{\circ} \mathrm{C}$ and $T_{\mathrm{L}}$ is the liquidus temperature of the given steel expressed as Eq. (1), Eq. (9) can be expressed as follows

$$
T=1536-\sum_{i}\left\{f\left(C_{i}\right) \cdot\left[1-2 \Omega^{i} k^{i}\right]^{\left(k^{i}-1\right) /\left(1-2 \Omega^{i} k^{i}\right)}\right\}
$$

where superscript $i$ denotes solute element. However, Eq. (10) is not suitable to describe characteristic temperature, because various parameters such as $k^{i}, D_{\mathrm{s}}^{i}, \alpha^{i}$ and $\Omega^{i}$ are very complex coefficient of solute element. Therefore, characteristic temperature must be easily described to carbon equivalent, $\sum_{i} f^{\prime}\left(C_{i}\right)$, which is taken into account effect of various parameters such as $k^{i}, D_{\mathrm{s}}^{i}, \alpha^{i}$ and $\Omega^{i}$. Thus, characteristic temperature can be expressed as follows.

$$
\begin{aligned}
& T=1536-\left[\sum_{i} f^{\prime}\left(C_{i}\right)\right] \cdot\left[1-f_{\mathrm{s}}(1-2 \Omega k)\right]^{(k-1) /(1-2 \Omega k)} \\
& \Omega=\alpha(1-\exp (-1 / \alpha))-\frac{1}{2} \exp (-1 / 2 \alpha), \quad \alpha=A \cdot \dot{T}^{-m}
\end{aligned}
$$

where $f^{\prime}\left(C_{i}\right)$ is a function of the solute concentrations. The relation between the solid fraction and temperature can be determined from Eq. (11) at the given steel composition and cooling rate.

\section{Results and Discussions}

In order to determine the solid fraction in mushy zone as a function of temperature, the microsegregation of solute elements has been assessed. Many studies showed that ZST and ZDT correspond to the temperature at which the solid fraction becomes about $0.6491-$ $0.8^{26-28)}$ and $0.98-1.0,^{8,26,28)}$ respectively. Moitra et $a l .{ }^{27)}$ considered ZST as the temperature at the solid fraction of 0.7. Kobayashi ${ }^{26)}$ proposed that ZST and ZDT correspond to the temperature at which the solid fraction becomes 0.8 and 0.99 , respectively. From the high temperature tensile test of carbon steels, Nakagawa et al. ${ }^{8)}$ also proposed that ZDT corresponds to the temperature at which the solid fraction reaches 0.98 through the high temperature tensile test of carbon steel, and $\mathrm{Kim}^{28)}$ suggested that ZST and ZDT correspond to the temperatures at which the solid fraction becomes 0.6491 and 1.0 from the microsegregation analysis of various carbon compositions, respectively.

Using the microsegregation analysis, ZST and ZDT were calculated at various steel compositions and cooling rates in Table 2. Figure 3(a) shows the calculated ZST correspond to the temperatures at the solid fraction of $0.6491,0.7,0.75$ and 0.8 , along with the experimentally measured ZST by previous workers. ${ }^{4,6-10)}$ At the low carbon steel, the calculated ZST is much alike at the solid fraction of $0.6491-0.8$, but, at the high carbon steel, the calculated ZST is different from the experimentally measured ZST at various solid fractions. Figure 3(b) shows the calculated ZDT correspond to the temperature at the solid fraction of $0.98,0.99$ and 1.0 , along with the experimentally measured ZDT by previous workers. ${ }^{4,6-10)}$ At the solid fraction of 1.0 , the calculated ZDT deviate from the experimentally meaured ZDT. The solid fraction of 0.98 and 0.99 , the calculated ZDT is much alike to the experimentally measured ZST. The extremes, means and standard deviations of the dif- 
ferences between the measured and calculated temperatures, are presented in Table 3. Within the population of 45 carbon steels, ZST and ZDT at which the solid fraction becomes 0.75 and 0.99 , respectively, show the minimum mean value and standard deviation. At the solid fraction of 0.75 and 0.99 , the calculated ZST and ZDT by microsegregation analysis in the given condition of steel compositions and cooling rates are in reasonable agreement with the experimentally measured ZST and ZDT, as shown in Figs. 3(a) and 3(b). In this study, authors determined ZST and ZDT as the temperatures where the solid fraction is 0.75 and 0.99 , respectively.

The prediction equations for ZST, LIT and ZDT depend on cooling rate and steel composition are derived from the experimentally measured data of previous
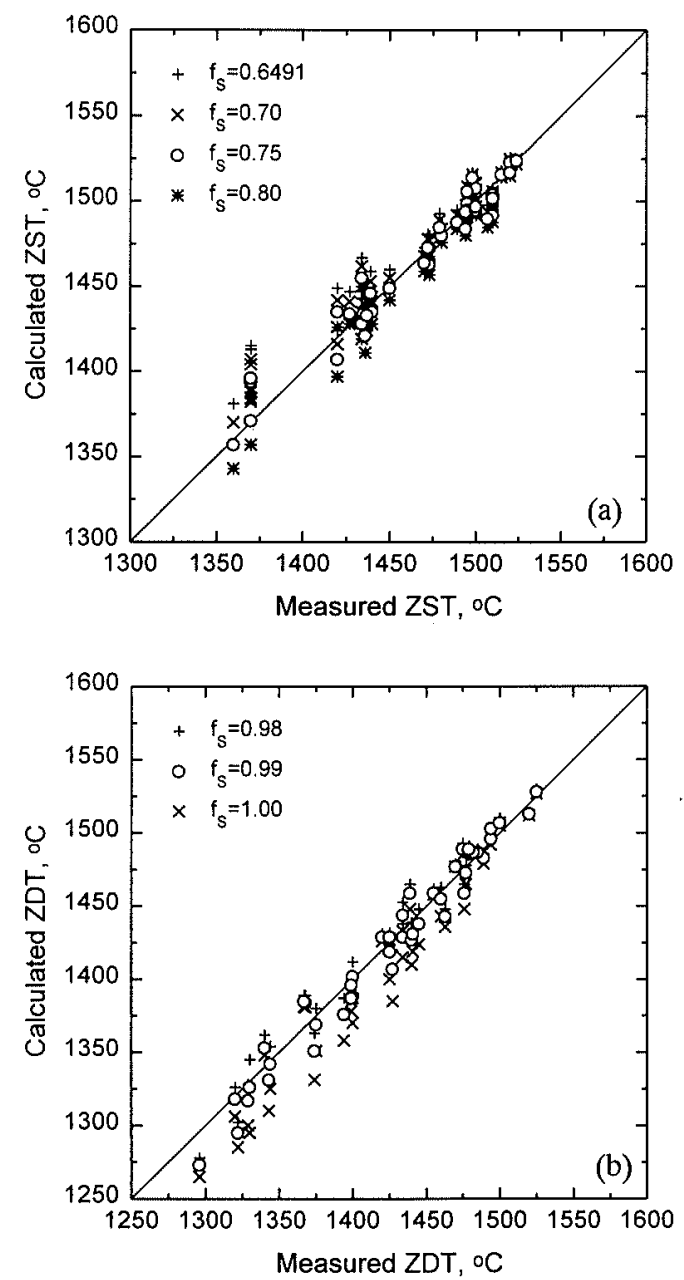

Fig. 3. The calculated (a) ZST and (b) ZDT using the microsegregation analysis along with the experimentally measured data of ZST and ZDT by previous workers, ${ }^{4.6-10)}$ respectively. workers ${ }^{4,6-10)}$ as shown in Figs. 3(a) and 3(b). The corresponding solid fractions for ZST, LIT and ZDT were $0.75,0.9$ and 0.99 , respectively. And, $k$ and $A$ are assumed as a constant parameter. The experimentally measured ZST and ZDT data were best fitted by Eq. (11) to obtain parameters as follows.

$$
\begin{array}{r}
T=1536-\left[\sum_{i} f^{\prime}\left(C_{i}\right)\right] \cdot\left[1-f_{\mathrm{s}}(1-2 \Omega k)\right]^{(k-1) /(1-2 \Omega k)} \\
\sum_{i} f^{\prime}\left(C_{i}\right)=67.51(\mathrm{wt} \% \mathrm{C})+9.741(\mathrm{wt} \% \mathrm{Si})+3.292(\mathrm{wt} \% \mathrm{Mn}) \\
+82.18(\mathrm{wt} \% \mathrm{P})+155.8(\mathrm{wt} \% \mathrm{~S}) \quad \ldots \ldots \ldots \ldots . . .12) \\
\Omega=\alpha(1-\exp (-1 / \alpha))-\frac{1}{2} \exp (-1 / 2 \alpha), \\
\alpha=33.7 \cdot \dot{T}^{-0.244}
\end{array}
$$

where the value of $k$ is 0.265 , which is the average value of $k^{\delta / \mathrm{L}}$ and $k^{\gamma / \mathrm{L}}$ of carbon. Because the equilibrium distribution coefficient at low and middle carbon concentration, at which the peritectic reaction occurs, cannot take into account in prediction equation.

From the Clyne-Kurz model of Eq. (10) and the prediction equation, the relationship among the various parameters such as carbon equivalent, $f_{\mathrm{s}}, k^{i}, D_{\mathrm{s}}^{i}, \alpha^{i}$ and $\Omega^{i}$, has been expressed as follows

$$
\begin{aligned}
\sum_{i} \Delta T_{i} & =\sum_{i}\left\{f\left(C_{i}\right) \cdot\left[1-f_{\mathrm{s}}\left(1-2 \Omega^{i} k^{i}\right)\right]^{\left(k^{i}-1\right) /\left(1-2 \Omega^{i} k^{i}\right)}\right\} \\
& =\left[\sum_{i} f^{\prime}\left(C_{i}\right)\right] \cdot\left[1-f_{\mathrm{s}}(1-2 \Omega k)\right]^{(k-1) /(1-2 \Omega k)}
\end{aligned}
$$

where

$$
\begin{aligned}
\Delta T_{\mathrm{C}}= & 78(\mathrm{wt} \% \mathrm{C}) \cdot\left[1-f_{\mathrm{s}}\left(1-2 \Omega^{\mathrm{C}} k^{\mathrm{C}}\right)\right]^{\left(k^{\mathrm{c}}-1\right) /\left(1-2 \Omega^{\mathrm{C}_{k} \mathrm{c}}\right)} \\
= & 67.51(\mathrm{wt} \% \mathrm{C}) \cdot\left[1-f_{\mathrm{s}}(1-2 \Omega k)\right]^{(k-1) /(1-2 \Omega k)} \\
& \vdots \\
\Delta T_{\mathrm{S}}= & 38(\mathrm{wt} \% \mathrm{~S}) \cdot\left[1-f_{\mathrm{s}}\left(1-2 \Omega^{\mathrm{S}} k^{\mathrm{S}}\right)\right]^{\left(k^{\mathrm{S}}-1\right) /\left(1-2 \Omega^{\mathrm{s}} \mathrm{s}^{\mathrm{s}}\right)} \\
= & 155.8(\mathrm{wt} \% \mathrm{~S}) \cdot\left[1-f_{\mathrm{s}}(1-2 \Omega k)\right]^{(k-1) /(1-2 \Omega k)}
\end{aligned}
$$

To compare $\Delta T_{i}$ of various solute elements, the $0.48 \mathrm{C}-$ $0.2 \mathrm{Si}-1.0 \mathrm{Mn}-0.013 \mathrm{P}-0.011 \mathrm{~S}$, which is the averaged steel compositions in Table 2, has been calculated using the Eq. (13). Figure 4 shows the calculated $\Delta T_{i}$ by the Clyne-Kurz model using the data in Table 1 compared with the predicted $\Delta T_{i}$ by Eq. (13). The calculated $\Delta T_{i}$ by prediction equation are in reasonable agreement with the calculated $\Delta T_{i}$ by Clyne-Kurz model at various solute elements. Therefore, the proposed prediction equation, at which $k$ is assumed as constant value, can be described to characteristic temperatures as carbon equivalent.

The non-equilibrium pseudo binary $\mathrm{Fe}-\mathrm{C}$ phase diagram was calculated using the microsegregation anal-

Table 3. Statistical assessment for determination of solid fraction on ZST and ZDT.

\begin{tabular}{l|cccc|ccc}
\hline Characteristic Temperature & \multicolumn{4}{|c|}{ ZST } & \multicolumn{3}{|c}{ ZDT } \\
\hline Solid Fraction, $f_{s}$ & 0.65 & 0.7 & $\mathbf{0 . 7 5}$ & 0.8 & 0.98 & $\mathbf{0 . 9 9}$ & 1.0 \\
\hline Measured-Calculated, K & & & & & & & \\
$\quad$ Max. & 11 & 14 & $\mathbf{1 8}$ & 25 & 20 & $\mathbf{2 7}$ & 43 \\
Min. & -45 & -37 & $\mathbf{- 2 6}$ & -18 & -26 & $\mathbf{- 2 0}$ & -14 \\
Mean & -9.87 & -5.49 & $\mathbf{- 0 . 4 1}$ & 5.18 & -4.16 & $\mathbf{2 . 3 3}$ & 11.8 \\
Standard Deviation & 12.46 & 11.23 & $\mathbf{1 0 . 2 5}$ & 10.82 & 10.51 & $\mathbf{1 0 . 4 9}$ & 17.14 \\
\hline
\end{tabular}




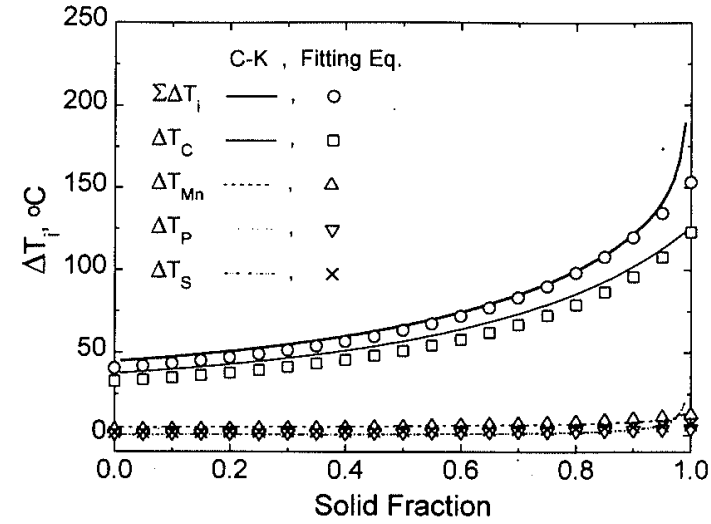

Fig. 4. Comparison of the calculated $\Delta T_{i}$ of various solute elements by the Clyne-Kurz model and prediction equation.
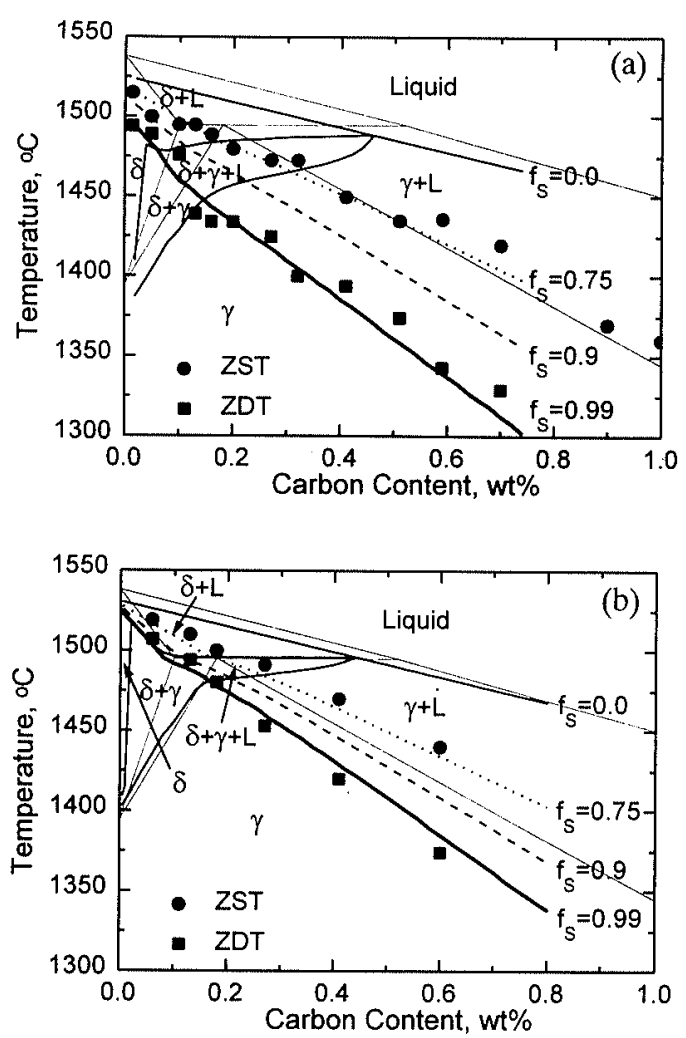

Fig. 5. Non-equilibrium pseudo binary $\mathrm{Fe}-\mathrm{C}$ phase diagram of (a) $0.34 \mathrm{Si}-1.52 \mathrm{Mn}-0.012 \mathrm{P}-0.015 \mathrm{~S}$ carbon steel and (b) $0.015 \mathrm{Si}-1.05 \mathrm{Mn}-0.0009 \mathrm{P}-0.0008 \mathrm{~S}$ carbon steel, along with the measured ZST and ZDT. ${ }^{6,7)}$

ysis. Schmidtmann et al. ${ }^{6)}$ and Shin et al. ${ }^{7)}$ measured ZDT and ZST of two carbon steels B1 and Cl in Table 2 as a function of carbon content. Figures 5(a) and 5(b) show the calculated non-equilibrium phase diagram compared with the measured data. The thick solid lines represent the non-equilibrium pseudo $\mathrm{Fe}-\mathrm{C}$ phase diagram and the thin lines represent the equilibrium binary $\mathrm{Fe}-\mathrm{C}$ phase diagram. The complete solidification temperature, i.e. the temperature at which the solid fraction, $f_{\mathrm{s}}$ becomes 1 , is about $50-100^{\circ} \mathrm{C}$ lower than the equilibrium solidus temprature. In sample $\mathrm{B} 1$ at carbon concentrations lower than about $0.05 \mathrm{wt} \% \mathrm{C}$, $\delta / \gamma$ transformation takes place after solidification, whereas at carbon concentrations higher than about

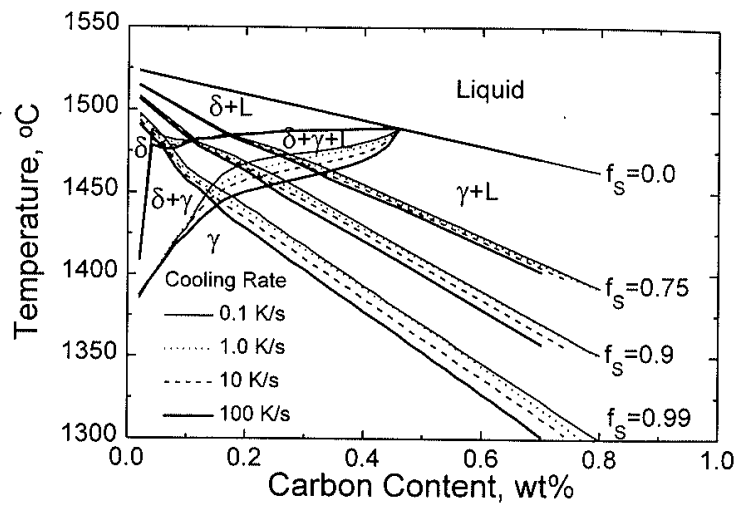

Fig. 6. Effect of cooling rate on the characteristic temperatures such as $T_{L}\left(f_{\mathrm{s}}=0.0\right), \operatorname{ZST}\left(f_{\mathrm{s}}=0.75\right), \operatorname{LIT}\left(f_{\mathrm{s}}=0.9\right)$ and ZDT $\left(f_{\mathrm{s}}=0.99\right)$ of $\mathrm{BL}$ near their melting point.

$0.05 \mathrm{wt} \% \mathrm{C}, \delta / \gamma$ transformation takes place during solidification. The calculated complete solidification temperatures are in good agreement with ZDT measured by Schmidtmann. ${ }^{6)}$ In the temperature range between ZDT and LIT, which is known as brittle temperature range, the steel shows hot tear under applied tensile stress state by thermal and mechanical deformation. In the brittle temperature range, the solidifying steel begins to behave like solid susceptible to crack due to no liquid feeding between dendrite arms. As shown in Fig. 5, above ZDT, the steel is not fully solidified due to microsegregation. Thus, hot tears mainly depend on the presence of the interdendritic liquid films due to the microsegregation of solute elements. But, hot tears formed between LIT and ZST can be refilled with the surrounding liquid. The measured ZST agrees with the temperature at which the solid fraction becomes about 0.75 as shown in Fig. 5. At the temperature between ZDT and ZST, the steel has no ductility due to interdendritic liquid film, but strength due to mechanical network between dendrites. Above ZST, the steel has no strength and no ductility, and behave as a liquid.

Using the microsegregation analysis, ZST, LIT and ZDT have been computed to investigate the effect of cooling rate for steel compositions of B1 in Table 2 . Figure 6 shows the non-equilibrium pseudo binary $\mathrm{Fe}-\mathrm{C}$ phase diagrams for steel compositions of $\mathrm{B} 1$ at various cooling rates of $0.1,1,10$ and $100^{\circ} \mathrm{C} / \mathrm{sec}$. The $f_{\mathrm{s}}$ of 0.0 , $0.75,0.9$ and 0.99 are corresponded to the characteristic temperature of $T_{\mathrm{L}}, \mathrm{ZST}$, LIT and ZDT, respectively. The complete solidification temperature decreases and the mushy zone of $\delta+\gamma+\mathrm{L}$ extends with increasing cooling rate from 0.1 to $100^{\circ} \mathrm{C} / \mathrm{sec}$. The effect of cooling rate on $T_{\mathrm{L}}$ is not significant, whereas the effect of the cooling rate on ZST, LIT and ZDT is significant due to the segregation of solute elements near the final stage of solidification with increasing cooling rate. Thus, ZST, LIT and ZDT with increasing cooling rate extend to lower temperature with increasing carbon content as shown in Fig. 6.

Figures 7(a) and 7(b) show the predicted ZST and ZDT by Eq. (12) in the given condition of steel compositions and cooling rates, along with the experimentally measured data, ${ }^{4,6-10)}$ respectively. At the given condition of steel compositions and cooling rates, the predicted 
ZST and ZDT are in reasonable agreement with the experimentally measured data.

Figures 8(a), 8(b) and 8(c) show the calculated ZST, LIT and ZDT by microsegregation analysis in the given condition of steel compositions and cooling rates, along with the predicted ZST, LIT and ZDT by Eq. (12), respectively. A good correlation on ZST, LIT and ZDT between the microsegregation analysis and the prediction equation are shown at various steel compositions and cooling rates.

The prediction equations of the characteristic temperatures such as ZST and ZDT has been suggested by previous researchers. ${ }^{4,13,39)}$ Table 4 shows the coefficient of solute element estimated from Eq. (12), comparing with others. Yu et al. ${ }^{4)}$ and Kawawa ${ }^{13)}$ proposed that prediction equations for ZST and ZDT, re-
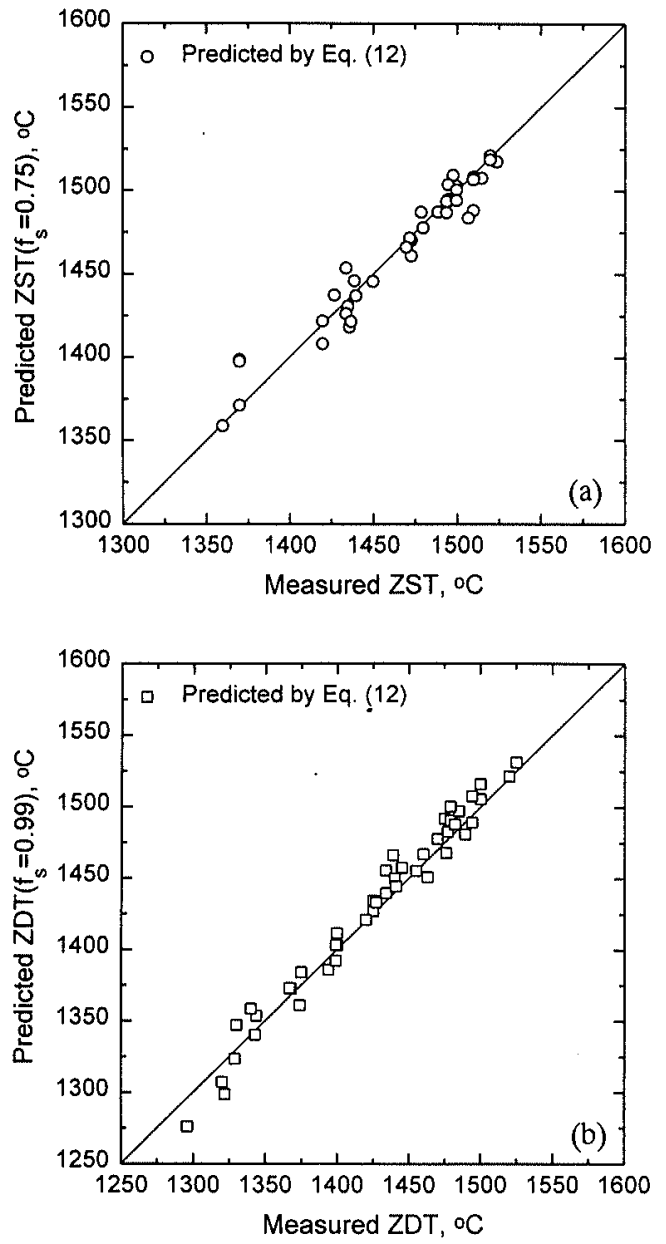

Fig. 7. The predicted (a) ZST and (b) ZDT by Eq. (12) along with the experimentally measured data of ZST and ZDT by previous workers, ${ }^{4.6-10)}$ respectively.
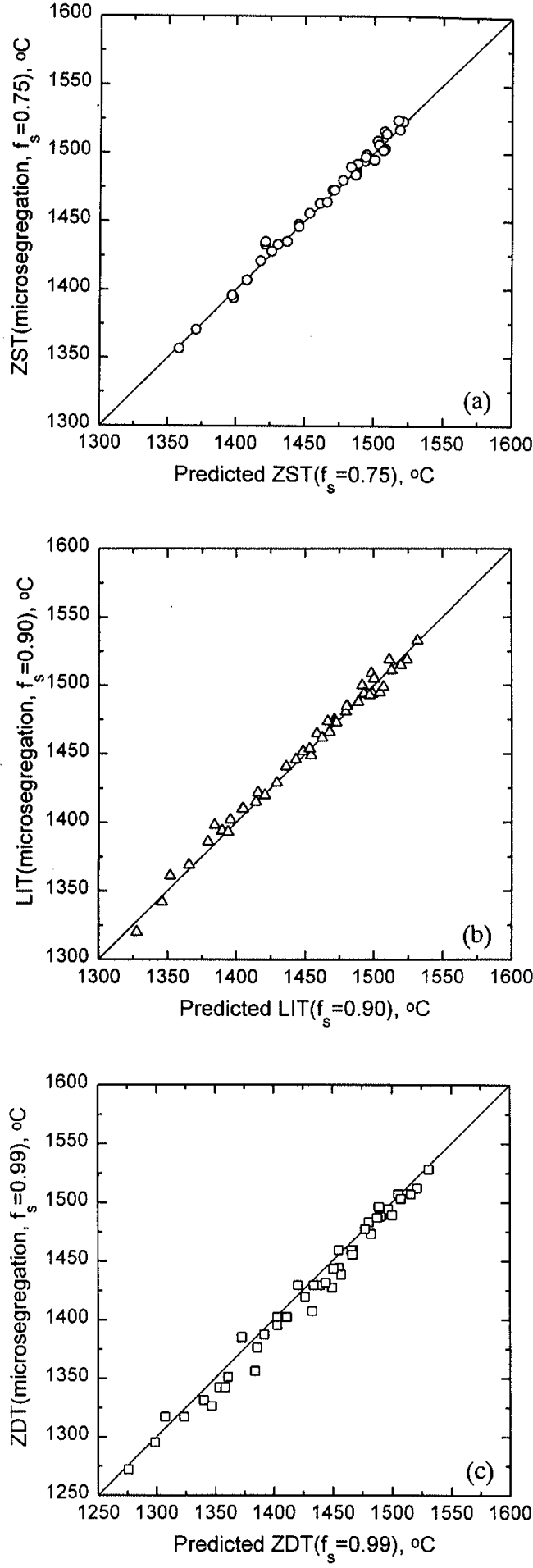

Fig. 8. The calculated (a) ZST, (b) LIT and (c) ZDT by microsegregation analysis in the given condition of steel compositions and cooling rates, along with the predicted ZST, LIT and ZDT by Eq. (12), respectively.

Table 4. Comparison of coefficient in the equation for characteristic temperatures.

\begin{tabular}{c|c|cc|c}
\hline Characteristic Temperature & ZST & \multicolumn{2}{|c|}{ ZDT } & ZST, LIT and ZDT \\
\hline Element & Yu $^{4)}$ & Kawawa $^{(3)}$ & Nagata $^{29}$ & This work \\
\hline $\mathrm{C}$ & 447.2 & 415.5 & $513.9^{*}$ & $\mathbf{6 7 . 5 1}$ \\
$\mathrm{Mn}$ & 14.8 & 6.8 & 6.5 & $\mathbf{3 . 2 9 2}$ \\
$\mathrm{Si}$ & & 12.3 & 20.5 & $\mathbf{9 . 7 4 1}$ \\
$\mathrm{P}$ & 658.8 & 124.5 & 1163 & $\mathbf{8 2 . 1 8}$ \\
$\mathrm{S}$ & 1553.6 & 183.9 & 2111 & $\mathbf{1 5 5 . 8}$ \\
\hline Consideration of cooling rate & NO & NO & NO & YES \\
\hline
\end{tabular}

* This coefficient is applied below $0.1 \mathrm{wt} \% \mathrm{C}$ steel. 


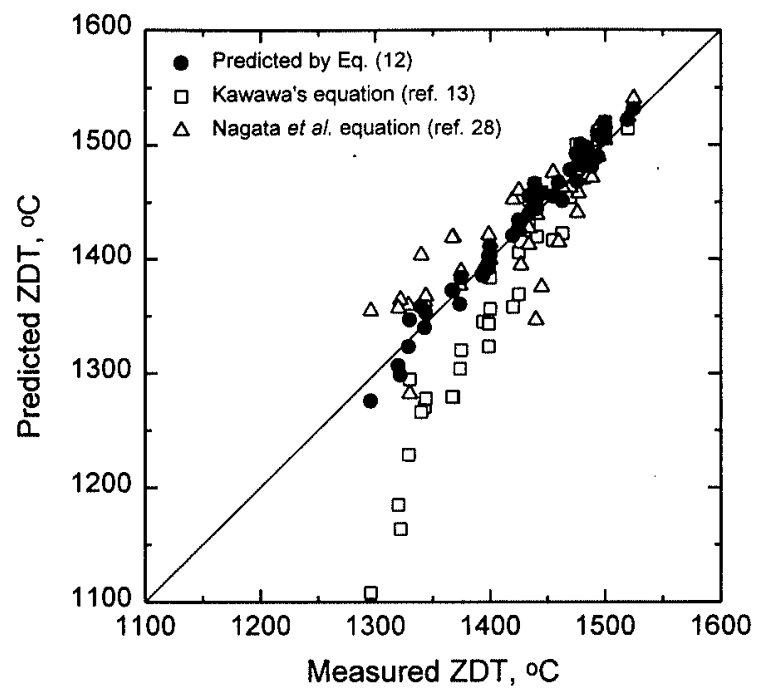

Fig. 9. Comparison of the predicted $\mathrm{ZDT}$ by previous workers. $^{13,29)}$

spectively, depend on only steel compositions, without taking into account the effect of cooling rate. The coefficient for solute element shows the degree of microsegregation i.e.; the larger value of coefficient means the larger segregation and lower solidification temperature.

Nagata et al. ${ }^{29)}$ suggested that the coefficient for $\mathrm{C}$ is given as a function of carbon concentration. The coefficients for solute elements in Eq. (12) are smaller than those in the previous prediction equations, but this does not mean that Eq. (12) underestimate the degree of microsegregation because Eq. (12) takes into account cooling rate. The degree of the microsegregation of sulfur at liquid film is the largest among other solute elements, and the characteristic temperatures are sensitive to the concentration of sulfur, phosphorous and carbon in order.

Figure 9 shows the calculated ZDT from Eq. (12) and that from Kawawa ${ }^{13)}$ and Nagata et al. ${ }^{29)}$ in the given condition of steel compositions, along with the experimentally measured data of ZDT. ${ }^{4,6-10}$ At the low carbon concentration (high ZDT), the calculated ZDT from Eq. (12), Kawawa and Nagata are in good agreement with experimentally measured data. At the high carbon concentration (low ZDT), the calculated ZDT from Eq. (12) predicted well comparing with that from others. With increasing carbon concentration, the effect of solute microsegregation on the solidification behavior increases. ${ }^{2)}$ Thus Eq. (12), which can take into account the cooling rate, could be useful to describe solidification behavior of high carbon steel.

\section{Conclusions}

An equation for ZST, LIT and ZDT was proposed, which can take into account the steel composition and cooling rate. From the microsegregation analysis, in comparison with experimentally measured data of ZST and ZDT, the temperature at which the solid fraction becomes $0.75,0.9$ and 0.99 corresponded to ZST, LIT and ZDT, respectively.

The effect of cooling rate on $T_{\mathrm{L}}$ was not significant, whereas the effect of cooling rate on ZST, LIT and ZDT were significant due to the severe of segregation of solute elements at the final stage of solidification which is influenced by the cooling rate. The degree of the microsegregation of sulfur at liquid film is the largest among other solute elements, and the characteristic temperatures are sensitive to the concentration of sulfur, phosphorus and carbon in order. The ZST, LIT and ZDT can be successfully described by the suggested prediction equation in the given range of steel compositions especially at the high carbon concentration and cooling rates.

\section{REFERENCES}

1) J. K. Brimacombe: Metall. Trans., 24B (1993), 917.

2) K. H. Kim, T. Yeo, K. H. Oh and D. N. Lee: ISIJ Int., 36 (1996), 284.

3) F. Weinberg: Metall. Trans., 10B (1979), 219.

4) C. H. Yu, M. Suzuki, H. Shibata and T. Emi: Mater. Trans., JIM, 37 (1996), 1251.

5) A. A. Howe: Ironmaking Steelmaking, 15 (1988), 134.

6) E. Schmidtmann and F. Rakoski: Arch. Eisenhüttenwes., 54 (1983), 357.

7) G. Shin, T. Kajitani, T. Suzuki and T. Umeda: Tetsu-to-Hagané, 78 (1992), 587.

8) T. Nakagawa, T. Umeda, J. Murata, Y. Kamimura and N. Niwa: ISIJ Int., 35 (1995), 723.

9) H. G. Suzuki, S. Nishimura and Y. Nakamura: Trans. Iron Steel Inst. Jpn., 24 (1984), 54.

10) Y. Yoshima, M. Fuji, T. Moriya, C. Matsumoto and S. Maruhashi: Renzokutyuuzou-ni-okeru-Rikigakutekikyodou, Joint Soc. on Iron and Steel Basic Research, ISIJ, Tokyo, (1985), 56.

11) Y. Ueshima, S. Mizoguchi, T. Matsumiya and H. Kajioka: Metall. Trans., 17B (1986), 845.

12) K. H. Kim, K. H. Oh and D. N. Lee: Scr. Mater., 34(1996), 301.

13) T. Kawawa: Handbook of Iron and Steel, Vol. 1, ed. by ISIJ, 3rd ed., Maruzen, Tokyo, (1981), 205.

14) Metals Handbook, Vol. 8, 8th ed., ed. by T. Lyman, H. E. Boyer, W. J. Carnes and M. W. Chevalier, ASM, Metal Park, OH, (1973).

15) T. W. Clyne and W. Kruz: Metall. Trans., 13B (1982), 259.

16) H. Jacobi and K. Schwerdtfeger: Metall. Trans., 7A (1976), 811.

17) T. Edvardsson, H. Fredriksson and I. Svensson: Met. Sci. J., 10 (1976), 298.

18) H. Jones and W. Kurz: Metall. Trans., 11A (1980), 1265.

19) M. A. Taha, H. Jacobi, M. Imagumbai and K. Schwerdtfeger: Metall. Trans., 13A (1982), 2131.

20) Y. Ueshima, N. Komatsu, S. Mizoguchi and H. Kajioka: Tetsu-to-Hagané, 73 (1987), 1551.

21) G. Shin: Ph.D. Thesis, The Univ. of Tokyo, Tokyo, Japan, (1990).

22) S. Chu, J. Li, Z. Liu, Z. Shi and H. Fu: Metall. Trans., 25A (1994), 637.

23) M. Imagumbai: ISIJ Int., 34 (1994), 896.

24) M. El-Bealy: Scand. J. Metall., 24 (1995), 106.

25) J. O. Oh: Master Thesis, Seoul National Univ., Seoul, Korea, (1997).

26) S. Kobayashi: Tetsu-to-Hagané, 73 (1987), S896.

27) A. Moitra and B. G. Thomas: Steelmaking Conf. Proc., ISS/AIME, Dallas, 76 (1993), 657.

28) K. H. Kim: Ph.D. Thesis, Seoul National Univ., Seoul, Korea, (1996).

29) S. Nagata, T. Matsumiya, K. Ozawa and T. Ohashi: Tetsu-to-Hagané, 76 (1990), 214. 